\title{
AFEMINADOS DE VIDA OCIOSA: SEXUALIDAD, GÉNERO Y CLASE SOCIAL DURANTE EL FRANQUISMO
}

\author{
EFFEMINATE OF IDLE LIFE: SEXUALITY, GENDER \\ AND SOCIAL CLASS DURING FRANCOISM
}

\author{
Abel Díaz* \\ Universidad del País Vasco, Euskal Herriko Unibertsitatea. España
}

\begin{abstract}
RESUMEN: Hasta los años treinta del pasado siglo xx, la posición de clase fue un elemento que diluía la percepción de ciertos comportamientos refinados o afeminados como indicios de homosexualidad, asociándolos con modales aristocráticos. Durante el franquismo, sin embargo, esta dinámica sufrirá cambios significativos. Progresivamente, se constituyó un cuerpo homosexual esencializado, que estuvo afectado, en menor medida, por otras variables históricas ajenas a la sexualidad a la hora de juzgar qué se entendía por «inversión». Lo que este artículo trata de analizar, empleando documentación judicial, es cómo las variables de sexualidad, clase y género afectaron a la definición de la homosexualidad en aquellos procesos en los que los inculpados pertenecían a las clases acomodadas.
\end{abstract}

PALABRAS CLAVE: homosexualidad, clase social, género, cuerpo, franquismo.

ABSTRACT: Until the 1930s, a social class diluted the perception of refined or effeminate behaviors as a sign of homosexuality, associating them with aristocratic manners. During Francoism, however, this dynamic underwent significant changes. Progressively, an essentialized homosexual body, which was not defined by attitudes and sexual behaviors anymore, gained prominence. In this process, the social understanding of «inversion» changed too. By using judicial documentation, this article attempts to analyze how sexuality, social class and gender affected the definition of homosexuality when people from the upper and middle classes were prosecuted.

KEY WORDS: Homosexuality, Social class, Gender, Body, Francoism.

* Correspondencia a: Abel Díaz. Universidad del País Vasco/Euskal Herriko Unibertsitatea. Facultad de Ciencias Sociales y de la Comunicación. Departamento de Historia Contemporánea. Barrio Sarriena s/n, Leioa (Bizkaia) 48940 - abel.diaz@ehu.eus; abeldzdz@gmail.com - https://orcid.org/0000-0001-9966-3573

Cómo citar: Díaz, Abel (2021). "Afeminados de vida ociosa: sexualidad, género y clase social durante el franquismo»; Historia Contemporánea, 65, 131-162. (https://doi.org/10.1387/hc.20943).

Recibido: 20 junio, 2019; aceptado: 30 septiembre, 2019.

ISSN 1130-2402 - eISSN 2340-0277 / (C) 2020 UPV/EHU

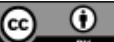

Esta obra está bajo una licencia

Creative Commons Atribución 4.0 Internacional 


\section{Introducción}

El 28 de abril de 1955, el Juez Especial de Vagos y Maleantes de Bilbao condenaba por el delito de «homosexualidad», al procesado en el expediente número 2 de ese mismo año, a cumplir «Internamiento en Institución especial para los homosexuales [...] con[f]orme dispone la Ley de 15 de julio de 1.954, por tiempo no inferior a DOS MESES NI SUPERIOR A UN AÑO» ${ }^{1}$. El proceso judicial tenía su origen en una denuncia por «escándalo público y corrupción de menores» y se hizo figurar que el «encartado» frecuentaba «reuniones habidas en casa de su hermano [...], a las que asistían jóvenes de 18, 19 y veintitantos años, todos varones, en las que bebían y bailaban y en alguna de ellas, en unión del citado hermano, hacían apología del homosexualismo». Además, uno de los participantes de aquella reuniones, al ser llamado como testigo, no dudó en dejar constancia en su manifestación que el investigado, al menos, «en una ocasión le propuso se acostara con él en la cama». Asimismo, el juez, para sustentar la condena, solicitó el concurso de un médico forense, como quedaba establecido en el protocolo de este tipo de procesos judiciales. En el informe, el médico constató que se trataba de un «homosexual» debido a que su «su manera de hablar, ademanes y actitudes, corresponden a los frecuentes en estos sujetos», es decir, ante él se presentaba un cuerpo asimilable a tal naturaleza de individuos. Esta apreciación de homosexualidad fue corroborada por otras instancias, la Jefatura Superior de Policía, la Comandancia de la Guardia Civil y el Ayuntamiento hicieron constar en sus respectivos informes que el investigado es «homosexual». Hasta este punto, el procedimiento abierto en el año 1955 seguía las pautas habituales de otros procesos abiertos por evidencias de desviación sexual por los Tribunales de Vagos y Maleantes, en aquellos años. La característica más singular de este expediente se deriva de las condiciones de vida, sociales y económicas, del procesado, que fueron también objeto de la investigación. Entre los «hechos probados» que ratificaban la condena,

1. La sentencia añadió el resto de medidas recogidas por la Ley de Vagos y Maleantes: La separación de los internos homosexuales del resto de los presos en los establecimientos penitenciarios; al finalizar la condena, la prohibición de residir en la provincia de origen durante un año y la obligación de declarar el domicilio durante este tiempo. Doc. 30994, Audiencia Provincial de Vitoria (1958), Sección Judicial, AHE. En general, la ortografía de la documentación consultaba es muy variable, y en el artículo se ha corregido para facilitar su lectura. 
figuraba que «ha vivido de lo que le producían los cargos de Director Gerente, que ha desempeñado [de] Presidente del Consejo, que desempeña actualmente, de la Cia. [...] así como de capital propio». Incluso, con el fin de hacer constar la solvencia del procesado, se añadió que «en una de tales reuniones otro de los testigos dice; le propuso le acompañase a otro domicilio y que el encartado le prometió llevarle en viaje de recreo a París con los gastos de cargo del encartado» ${ }^{2}$.

Aunque los estudios sobre la represión homosexual durante el franquismo han insistido generalmente en que la condición social acomodada resultaba un freno absoluto, para que las prácticas de determinados individuos fuesen objeto de persecución y condena, el presente proceso judicial nos permite hacer algunas matizaciones a esta afirmación. Lo que parte de la documentación analizada hasta el momento pone de relieve es que, aunque la condición social de los acusados por homosexualidad siempre fue un asunto a valorar por los tribunales, no fue el único elemento a la hora de juzgar la culpabilidad de los arrestados. Lo que estaba despuntando, en este proceso, fue un cuerpo homosexual, esencializado y caracterizado por su inadecuación en términos de género (manera de hablar, ademanes y actitudes), que relativizó el peso de la posición social acomodada en la construcción histórica de los significados de la desviación sexual. Fue el resultado de un intenso proceso de biologización que comenzó a evidenciarse, de forma más intensa, a partir de la década de los años cincuenta. Un momento de profundas transformaciones en relación con el ordenamiento de la sexualidad, de la que la reforma de la Ley de Vagos y Maleantes de 1954 es la expresión más visible, en este contexto. En este sentido, lo que tuvo lugar fue un cambio profundo en los significados de la sexualidad que provocaron no sólo nuevas formas de condena, sino que transformó profundamente su ontología en términos más amplios a los de la acción de la justicia. La homosexualidad, lejos de caracterizar exclusivamente a un conjunto de actos o deseos sexuales, pasará progresivamente a constituir una anatomía, reconocible en sí misma. En este sentido, ciertos comportamientos estéticos o refinados comenzaron a ser identificados también como formas de afeminamiento, a diferencia de lo que ocurría en las décadas precedentes, cuando la condición social de su portador los hacía resultar signos inequívocos de distinción de clase.

2. Sentencia del Juez Especial de Bilbao para la aplicación de la Ley de Vagos y Maleantes, 28/04/1955, expediente n. ${ }^{\circ}$ 2, Audiencia Provincial de Vitoria (1958), Sección Judicial, AHE/EAH. 
En términos diacrónicos, las investigaciones de que disponemos han señalado que desde la «aparición» de la homosexualidad a finales del siglo XIX hasta los años treinta del siglo XX, la condición social acomodada de un individuo podía liberarle de sospechas de disidencia sexual, entendiendo su comportamiento refinadamente afeminado no como un signo de inversión, sino como un marcador de distinción social ${ }^{3}$. Cabría preguntarse qué había ocurrido, con posterioridad a los años treinta, para que un sujeto de la posición social del procesado, en 1955, terminase siendo condenado, por su condición sexual. La hipótesis que se manejará en este artículo es que para la década de los años cincuenta, podemos documentar un proceso de intensificación en la conformación de un cuerpo homosexual singular y reconocible en sí mismo, al margen de otras variables identificativas. Por ello, el afeminado, fue convertido en la expresión más evidente de homosexualidad, y por tanto, pasó a ser el blanco de la represión sexual, con independencia de sus condiciones laborales o económicas. La desviación de género aparece, en la documentación analizada, como una condición generalizable a todos los condenados por sus prácticas/cuerpos sexualmente inadecuados, tanto entre los más acaudalados como entre los menos pudientes. Esta sustanciación de la disidencia sexual estaba radicada en la búsqueda de nitidez en la línea que debía separar los cuerpos «sanos» y cuerpos «abyectos», justificando, a su vez, la segregación social de los segundos. Este proceso de expulsión se fundamentó en la necesidad de mantener el orden de género, de refundar los significados desde los que se estaba construyendo la masculinidad normativa, en relación con los cambios históricos, a partir de la década de los años cincuenta y en adelante. No se trató, como se puede apreciar, de un proceso unidireccional ni definitivo, sino de un curso gradual en el que se entrecruzaron visiones médicas, jurídicas, sociales o religiosas conformando un panorama complejo.

3. La historiadora Nerea Aresti, analizando el contexto de finales de los años veinte y treinta, señalaba como la «clase social irrumpía [...] como factor decisivo a la hora de determinar lo que se consideraba comportamiento «normal» o síntoma de homosexualidad en un hombre». Aresti, 2010, p. 204. Ello no quiere decir que ciertos entornos aristocráticos de homosociabilidad estuviesen fuera de vigilancia durante este periodo, simplemente, que el castigo se centró más sobre los personajes que acompañaban al dandy, que sobre el propio aristócrata. En: Vázquez; Cleminson, 2011, p. 267. El proceso de esencialización de las sexualidades no normativas arranca mucho antes de la década de los cincuenta del siglo $\mathrm{xx}$, aunque se trata de un proceso discontinuo. En este sentido destacan los estudios: Vázquez, 2001; Vázquez; Cleminson, 2006; Cleminson, 2011. 
El franquismo representa, además, un periodo histórico singular para corroborar este proceso de biologización de la homosexualidad, especialmente a partir de los años cincuenta ${ }^{4}$. La condena de la homosexualidad, por parte de la dictadura, generó un amplio volumen de documentación judicial en la que las autoridades se vieron obligadas a codificar y definir qué entendieron por homosexualidad, y, como consecuencia de ello, provocar el nacimiento del cuerpo homosexual. Al mismo tiempo, y de forma explícita, esta documentación permite sopesar diversas variables, como la condición social, civil, política o laboral, a la hora de valorar su incidencia en la producción de significados sobre la sexualidad disidente ${ }^{5}$.

Parece evidente, aunque difícil de rastrear históricamente, que las prácticas sexuales no normativas de algunos jerarcas y grupos sociales afines al régimen franquista fueron más o menos consentidas ${ }^{6}$. Tolerancia y condena convivieron en un contexto dinámico. Este estudio no pretende evaluar cuantitativamente el fenómeno represivo, sino indagar en las reglas y tendencias que marcan su evolución histórica, generando espacios de transigencia o de escarmiento. En este sentido, en las próximas páginas se hará referencia más a la conformación de las subjetividades, a las transformaciones discursivas y a los cambios en los significados en torno a la homosexualidad, que al análisis de casuísticas concretas, que pueden resultar expresión de una gran variedad de formas de comprender la sexualidad.

En adelante se analizará, a través de una selección de documentación proveniente de diversas instancias de la administración judicial del País Vasco, este proceso de conformación de lo homosexual. Un proceso histórico que nos revelará una anatomía y un personaje, sexualmente desviado, que fue adquiriendo nitidez según nos aproximamos a finales de la década de $1960^{7}$.

4. La década de los cincuenta representa un momento singular para el periodo franquista tanto en el terrero político como en el de la gestión biopolítica de las poblaciones. Los cincuenta son el momento de tránsito entre lo que Salvador Cayuela denomina una biopolítica totalitaria (1939-1959) y una biopolítica desarrollista. Cayuela, 2014, pp. 39 y 207. Aunque los cambios en los imaginarios del cuerpo y la sexualidad no se puedan fechar de forma exacta, considero que resulta adecuado emplear como criterio temporal más genérico la década de 1950.

5. Para los estudios sobre homosexualidad y franquismo mirar: Díaz, 2019; Terrasa, 2016; Mora, 2016; Ugarte, 2008; Mira, 2007; Baidez, 2007; Sosa, 2006; Olmeda, 2004; Ugarte, 2004; y Arnalte, 2003. Para el estudio específico de las mujeres lesbianas bajo el franquismo: Albarracín, 2012, pp. 69- 87.

6. Miguel de Molina incluye una anécdota de estas características en sus memorias. Valverde, 1998, p. 288.

7. Los fondos judiciales del País Vasco resultan especialmente pertinente para los estudios sobre la represión homosexual durante el franquismo del norte peninsular, pues cen- 


\section{La configuración histórica del «personaje» homosexual.}

El filósofo Michel Foucault señaló que la relevancia del surgimiento de la noción de «homosexualidad» residía en la conformación de este particular tipo humano como un «personaje», como un sujeto que en todo su ser aparecía condicionado por su sexualidad. En otros periodos históricos, las relaciones entre personas del mismo sexo habían sido juzgadas negativamente, e incluso castigadas severamente. Sin embargo, en estos contextos su sexualidad representaba sobre todo una práctica errónea o un pecado, sin que el cuerpo (psicofísico) de los condenados constituyera una experiencia singular entre el resto de individuos. Así lo definía en su Historia de la sexualidad:

El homosexual del siglo XIX ha llegado a ser un personaje: un pasado, una historia y una infancia, un carácter, una forma de vida; asimismo una morfología, con una anatomía indiscreta y quizá misteriosa fisiología. Nada de lo que él es in toto escapa a su sexualidad ${ }^{8}$.

El cambio sustancial que representa el «nacimiento» de lo homosexual es la esencialización de los cuerpos y sus prácticas, la homosexualidad ya no es exclusivamente algo que se «hace», es algo que principalmente se «es». Algo que se aloja en el interior de los individuos pero que trasciende a la superficie, apoderándose de los mismos por completo. La sexualidad comprendida como una sustancia ha sido adherida indisociablemente a los sujetos sin posibilidad de distanciamiento. En este juego constante entre lo interno y lo externo es donde el cuerpo cobra singularidad, más allá de cualquier otro elemento, a la hora de juzgar la sexualidad de un sujeto ${ }^{9}$. Lo sexual ya no es algo que el individuo verbaliza, no se basa en el descubrimiento de prácticas sexuales en

tralizaba diversos territorios bajo su jurisdicción. Concretamente el Tribunal de Vagos y Maleantes de Bilbao actuó durante el periodo sobre las provincias de Vizcaya, Santander, Burgos, Álava y Logroño. La provincia de Guipúzcoa tuvo, durante la década de los sesenta tribunales propios (Tribunal de Vagos y Maleantes de San Sebastián), más tarde sería fusionado con el anterior. El número de expedientes consultados supera la centena en el caso los Tribunales de Vagos y Maleantes, y en torno a la veintena para la justicia ordinaria para la décadas de los cuarenta y los cincuenta.

8. Foucault, 1976, p. 56-57.

9. Para un mayor desarrollo de los debates historiográficos en torno al paradigma de la incorporación: Díaz Freire, 2007, pp. 22-27; Díaz Freire, 2003, pp. 66-70. 
lugares ocultos, tras su constitución como «personaje», lo homosexual es algo que los otros pueden descubrir acerca de una persona sin necesidad de su concurso.

Como se puede imaginar, el proceso histórico de conformación de este «personaje» homosexual no fue lineal, sino que estuvo sujeto a transformaciones históricas y contextos donde la sexualidad constituía un foco de atención más o menos central en cada momento y espacio. Por ello, aunque su «nacimiento» se remonte en muchos países occidentales al siglo XIX, en las diferentes instancias de producción discursiva, los procesos de conformación de este «personaje» nunca han sido homogéneos y estables, y se han reconfigurado de formas diversas a lo largo de las décadas y las tradiciones científicas de cada país. En todo caso, me interesa destacar la relevancia del proceso, ya que no se trata de un cambio meramente terminológico, sino de una transformación de los significados del cuerpo, las prácticas y la gestión social de los individuos. Matizando el análisis foucaultiano, Francisco Vázquez y Richard Cleminson han señalado acertadamente, que al historizar la homosexualidad deberíamos también prestar atención a los «cambios en las expectativas de género para cada uno de los sexos, y la persuasiva inestabilidad de los límites entre lo que culturalmente se considera como masculinidad y feminidad $»^{10}$. Los significados de la homosexualidad, como se podrá apreciar en las próximas páginas, estuvieron más vinculados con la adecuación o no de los cuerpos a los valores de la masculinidad normativa que con las prácticas sexuales de los sujetos. El afeminado desafiaba también el orden social en tanto que ponía en cuestión la diferencia sexual ${ }^{11}$.

La caracterización sexual de los sujetos históricos siempre estuvo cortada por múltiples variables, además de la de género. La posición social, por ejemplo, representa en este estudio un condicionante especialmente singular. En lo referente a los estudios del franquismo ha sido uno de los elementos más debatidos. La obra de Geoffroy Huard ha sido la que con más rotundidad ha señalado la ausencia de individuos procesados por homosexualidad perteneciente a las clases acomodadas, analizando la documentación generada desde el Tribunal de Vagos y Maleantes barcelonés. Así, el autor ha señalado que los condenados por

10. Vázquez, 2018, pp. 115-128. Vázquez, 2012, pp. 13-21. Vázquez; Cleminson, 2011, p. 12.

11. En relación con el concepto de género empleado: Scott, 2011, pp. 98; Laqueur, 1994, p. 33; Butler, 2010, p. 25; Krylova, 2016. 
homosexualidad «pertenecían todos a las clases populares: la mayoría no tenía trabajo «honesto», ejercía la prostitución, y los demás eran obreros o empleados de baja categoría». Por tanto, que nunca fueron abiertos expedientes a personas pertenecientes a la clase media o de la burguesía y, que en conclusión, la justicia franquista actuó siempre como una «justicia de clase» ${ }^{12}$.

Es cierto que, en términos generales la justicia franquista castigó más la desviación sexual en las clases populares, si aplicamos una lógica cuantitativa en la consulta documental. El paso por los tribunales de los miembros de las clases medias y acomodadas fue numéricamente inferior, aunque no quedaron sistemáticamente libres de vigilancia, control y procesamiento por las autoridades, por sus conductas sexuales consideradas inapropiadas. Por tanto, la pertenecía social no fue tomada siempre como un patrón fijo e inquebrantable en el procesamiento judicial de la homosexualidad, sino que en muchos casos, fue el género el que constituyó el elemento más definitorio en la valoración de determinadas conductas sexuales como reprobables. Este dato también es deducible de la consulta de fuentes disponibles para otros territorios diferentes al País Vasco. Por tanto, lo que se buscará en adelante es comprender qué elementos resultaron singulares para hacer de la condición sexual de determinados individuos una situación condenable o no ${ }^{13}$. En este aspecto también atenderé a las reflexiones de Michel Foucault cuando trataba de valorar de forma general el impacto de los factores económicos en los procesos represivos. Foucault señalaba como, atribuyendo a la represión sexual un origen puramente económico, se perdía de vista toda una serie de refuerzos e intensificaciones» que hicieron aparecer la «discordan-

12. Huard, 2014, p. 104; Huard, 2016; Huard, 2018. En el mismo sentido se ha pronunciado Javier Ugarte, «los homosexuales que tenían dinero o estaban bien relacionados podían vivir tranquilamente» siempre que tuviesen una mínima discreción. Ugarte, 2008, p. 14. Para ampliar su reflexión sobre el vínculo entre clase y represión homosexual, mirar: Ugarte, 2011.

13. Una de las razones por las que considero que no pueden emitirse juicios de valor cerrados respecto a la pertenencia social de los procesados sexuales durante el franquismo deriva de las propias condiciones de conservación de la documentación judicial. Los criterios de catalogación y depósito de los fondos responde muchas veces más a qué instancia judicial produjo los expedientes, que al propio contenido de la documentación; como las distinciones de tipo administrativo (justicia ordinaria o especial), entre otras. Sumado a ello, la práctica de expurgos derivados del alto volumen físico, que dicha tipología documental requiere para su conservación, hace que no se disponga en algunos casos del volumen total de documentación generada. Por ello, el acceso siempre tendrá un carácter parcial. 
cia sexual». Por tanto deberíamos atender a la proliferación de discursos y dispositivos, exigencias de poder que generan, entre otros, «un sistema de saber legítimo y de una economía de placeres múltiples» ${ }^{14}$. Siguiendo esta propuesta, a lo que habría que prestar atención es a los mecanismos que hacen surgir al «cuerpo homosexual» como una experiencia separada del resto del cuerpo social, mecanismos que seleccionan y atribuyen relevancia a determinados aspectos, que de otra manera resultarían irrelevantes. No planteo aquí, sin embargo, resaltar exclusivamente lo que Foucault denominaba «saberes expertos» sino indagar en todo el conjunto de instancias que colaboraron a ordenar y codificar la sexualidad desde múltiples campos sociales ${ }^{15}$.

Desde mi punto de vista, lo que cabría preguntarse es si en realidad las prácticas de las élites y de los grupos populares eran las mismas, o su configuración y sus significados eran diferentes, dentro de un mismo contexto histórico. La cuestión gira en torno a cómo el propio régimen franquista, que desarrolló el conjunto normativo más duro en su persecución de la homosexualidad a lo largo del siglo Xx en el Estado español, toleró determinadas prácticas homosexuales. Pero, al mismo tiempo, cuándo y bajo qué circunstancias éstas fueron o no toleradas, evitando una visión monolítica del régimen en materia sexual y atendiendo con precisión a las transformaciones y desplazamientos sutiles que fueron teniendo lugar, a lo largo de los años. Qué estaba detrás de esta tolerancia, la cuestión de clase únicamente o actuaban otros factores dando forma a esta realidad. Llegando incluso a plantearnos si, en realidad, debemos hablar no tanto de «homosexualidad» como de «homosexualidad(es)» que conviven en un mismo tiempo y espacio ${ }^{16}$.

Por otra parte, la relación entre clase y sexualidad no puede establecerse de manera directa, siempre estuvo matizada por las visiones subjetivas de los actores históricos en el pasado. En este sentido, una anécdota carcelaria, recogida por la historiadora Nerea Aresti, resulta tremenda-

14. Foucault, 1976, p. 91.

15. Como se ha señalado desde hace tiempo, la insistencia en la historicidad tiene como principal precaución evitar una compresión «naturalizada» de la sexualidad y generar posibles anacronismos, en: Vázquez; Moreno, 1997, p. 13. Otras referencias teóricas en este sentido: Vázquez; Cleminson, 2011, pp. 5-8; Cabrera, 2001, pp. 51-54; Aresti, 2010, pp. 20-23; Vázquez, 2009, pp. 3-14.

16. Vázquez, 2012. Mary Nash insistía en cuestionar estos esquemas rígidos y binarios como forma de historizar las complejidades subyacentes a la historia de género, en relación con las condiciones sociales. Nash, 2003, p. 25. 
mente explicativa. En ella, Gregorio Marañón recuerda su paso por la prisión en el contexto de la dictadura de Primo de Rivera:

Pues estaba yo en la cárcel, como detenido político, con varios más y estábamos en pijama. Entró una cuerda de presidiarios que no nos habían visto aún y parándose delante de nosotros dijeron en alta voz una palabra más clásica que homosexual, con la que nos calificaban. Nuestros pijamas y rostros rasurados fue[ron] bastante para la identificación popular ${ }^{17}$.

Lo que se puede extraer de esta situación es que la mirada de origen popular pudo considerar determinados hábitos aristocráticos como signos, seguramente menos de desviación sexual, como sí de carencia de «virilidad». Por ello, a la hora de juzgar esta relación entre sexualidad y clase resulta fundamental comprender los espacios desde los que se realizan las enunciaciones y vislumbrar, en la medida de lo posible, si estamos aproximándonos a comprensiones diferentes de la sexualidad o de la masculinidad a la hora de juzgar una situación. Al fin y al cabo, lo que estaba en juego en relación con la homosexualidad durante el franquismo fue la salvaguarda de la virilidad en los hombres ${ }^{18}$.

\section{Entre los «viejos delitos» y el despunte del «cuerpo homosexual».}

Aunque generalmente se ha insistido en el carácter homófobo del régimen franquista, la penalización explícita de este tipo de conductas y cuerpos no fue implantada de forma inmediata en el contexto de posguerra, al contrario, tuvo un desarrollo cronológico particular. En general, los supuestos legales desde los que la homosexualidad fue enjuiciada no fueron una innovación del régimen, y en gran medida, o se reactivaron fórmulas preexistentes o se reformaron algunos apartados incorporando nuevos tipos penales.

En lo que aquí nos interesa, en relación con la configuración de subjetividades, los supuestos legales estuvieron caracterizados por una enorme

17. Aresti, 2010, pp. 204-205.

18. Para los estudios sobre la masculinidad durante el franquismo: Di Febo, 1991; Di Febo, 2003; González, 2005; Vincent, 2006; Vincent, 2018; Alegre, 2012; Rosón, 2013; Aresti, 2014; Rincón, 2014; Box, 2016; Box, 2017; Alcalde, 2017. 
ambigüedad y una escasa definición. El artículo 431 del Código Penal reguló a partir de 1944 el «escándalo público», que fue definido de la siguiente manera: «Los que de cualquier modo ofendieran el pudor o las buenas costumbres con hechos de grave escándalo o trascendencia», haciendo recaer el peso en la subjetividad del observante, que establecería el grado de ofensa. El artículo 430 reconocía al autor de «abusos deshonestos» como «el que abusare deshonestamente de persona de uno u otro sexo [...]». Por último, la Segunda Enmienda a la Ley de Vagos y Maleantes (1933), aprobada en 1954, sumó a la legislación la «homoxesualidad [sic]» como delito, sin especificar exactamente en qué consistía ${ }^{19}$. En términos prácticos, la definición de homosexualidad quedó entonces en manos de jueces, forenses, policías, denunciantes o testigos, que a través de su participación en los procesos judiciales fueron plasmando sus diversas percepciones del delito sexual. Podríamos suponer que en la valoración de situaciones «escandalosas» tuviese un peso más central las acciones de los inculpados, a priori, que sus cuerpos. Del mismo modo, un abuso, haría referencia a un hecho puntual; y la penalización de la homosexualidad, en sí misma, nos remitiría a una definición más cerrada. La realidad fue que estos tipos legales se emplearon de forma ambigua, y en muchos casos se superpusieron en la búsqueda de evidencias firmes para justificar las condenas.

En los procesos abiertos en la década de los cuarenta, mayoritariamente bajo el supuesto de «escándalo público», la condición social de los inculpados resultó totalmente irrelevante a la hora de penalizar o absolver las prácticas sexuales de los investigados. En la documentación localizada para esta década, los datos económicos o profesionales que no siempre figuran específicamente, y cuando lo hacen están exclusivamente circunscritos a recoger los datos de filiación. En ninguno de los casos estudiados existe una vinculación estrecha con circunstancias de marginalidad social

19. Cuello, 1946, p. 382-384. Las corrientes jurídicas que no especificaban explícitamente el contenido de los delitos o el tipo de sujetos sobre el que tenía que imponerse, se remontaban a las últimas décadas del siglo xix: Domingo, 1977, p. 24; y Terrasa, 2016, p. 109. Cleminson; Fernández; Vázquez, 2014, p. 373; Terrasa, 2004, pp. 83; y Terrasa, 2016, pp. 128-129. Para la Ley de Vagos y Maleantes mirar: BOE, 17/071954. Existen constancias de la aplicación de la Ley de Vagos y Maleantes sobre sujetos homosexuales antes de 1954, aprovechando las ambigüedades del propio articulado: Heredia, 2009, pp. 109-120. Las continuidades entre unos sistemas políticos y otros son más que evidentes en materia sexual, el delito de «escándalo público» permaneció vigente con el fin del régimen franquista: Chamouleau, 2017, pp. 21-22. 
o práctica de la prostitución. Normalmente fueron el resultado de denuncias de unos particulares frente a otros, habitualmente dentro de la misma comunidad, de los que tenían sospechas por sus inclinaciones sexuales. Las comprensiones de la sexualidad que operaron en el trasfondo de estos juicios estaban directamente relacionadas con la moral católica y, por tanto, la sexualidad no normativa estuvo concebida como el desempeño de un acto sexual exclusivamente, y la recopilación de evidencias se centró en demostrar o no la existencia de los mismos. No resulta llamativo que los términos en los que se aludió a la desviación sexual fuesen los de «sodomía» $\mathrm{o}$ «actos de inversión» ${ }^{20}$, incluso en un expediente abierto sobre dos mujeres, la mujer que las denunció insistió en dejar constancia de que «estaban acostadas juntas» realizando «actos inmorales» ${ }^{21}$.

Las transformaciones más significativas llegaron con la década siguiente, que constituye un periodo significativo de transición en todos los órdenes durante la dictadura, especialmente también en la reactualización de los valores de género ${ }^{22}$. El expediente número 2 de 1955, que abría este artículo, resulta expresión de las tensiones que produjeron los cambios que comenzaban a generalizarse en la década de los años cincuenta. Aunque este proceso fue abierto por el Tribunal de Vagos y Maleantes, su origen estaba en una denuncia de «escándalo público». Los vecinos del procesado alertaban a las autoridades de «sus escandalosas juergas», que habían sido habituales y «conocidas», no tan «solo por el vecindario de la casa, sino por todos los de la localidad». Las prácticas escandalosas, expresadas por los testigos dieron origen al proceso, sin embargo, unas acciones que hubiesen sido indicativo inequívoco de delito en la década anterior, comenzaron a no resultar evidencias suficientemente sólidas para determinar que el procesado hubieses contravenido las normas. Por ello, las autoridades ampliaron sus investigaciones interrogando a cuatro de los «jóvenes» que habían pasado por las fiestas en casa del detenido. Las preguntas giraron en torno a los hechos ocurridos en el domicilio y, aún así, nunca llegaron a confir-

20. Documento 26349 (1949), Juzgado de Instrucción de Vitoria; Documento: 27669 (1943), Audiencia Provincial de San Sebastián; Documento: 27711 (1943), Audiencia Provincial de San Sebastián; y Documento: 27367, Audiencia Provincial de San Sebastián (1944). Sección Judicial, AHE/EAH.

21. Documento 27568 (1944), Audiencia Provincial de San Sebastián, Sección Judicial, AHE/EAH. Otro estudio reciente han remarcado el peso de las visiones católicas frente a las médico-científicas en la regulación de género durante la posguerra: Álvarez Fernández, 2020.

22. Morcillo, 2015, p. 8-9. 
mar la existencia de prácticas sexuales explícitas. Por el contrario, en lo que sí hubo un consenso general fue en la confirmación, por parte de estos testigos, de la «inversión» del anfitrión de las «juergas» 23 . Uno de los jóvenes afirmó de forma inequívoca que había «podido comprobar que son invertidos sexuales, cosa que no tienen ningún reparo en manifestar», confirmando las evidencias recogidas en el escrito del forense ${ }^{24}$. Aunque aquí el cuerpo «invertido» comenzaba a despuntar, se entremezclaba con comprensiones que venían de un tiempo anterior. Los actos sexuales, entendidos fundamentalmente como «penetración», que habían sido el espacio nuclear de la comprobación de la «sodomía» 25 comenzaban a resultar evidencias menos centrales. Los actos sexuales cedían paso lentamente al cuerpo material como fuente de escándalo, su sola presencia era indicio de transgresión, como evidenciaba la actitud de descaro del investigado, que no había tenido reparos en manifestar abiertamente su condición.

A diferencia del proceso del anfitrión acomodado, en otros expedientes judiciales, también en la década de los cincuenta, la progresiva biologización de la homosexualidad se observó de forma mucho más intensa y manifiesta. En el mes de enero de 1950, un médico vitoriano fue denunciado por «abusos deshonestos», acusado de haber tenido relaciones con un menor, de diecinueve años de edad y sordomudo, al que en ocasión de tener que asistir a su madre, que se encontraba enferma, «le tocó el pene hasta hacerle expulsar la esperma, a la vez que le besaba» ${ }^{26}$. El médico contó para su defensa en el proceso con un abogado, del que conservamos su escrito. En su alegato, el abogado trató de exculpar a su defendido de los delitos de «escándalo público» y de «abusos deshonestos», que en su redacción aparecen también aparecen entremezclados,

23. Como han señalado F. Vázquez y R. Cleminson: «homosexualidad se opone a la heterosexualidad, pero la "inversión" o el "estetismo" se oponen a la masculinidad», reiterando el matiz de género. Vázquez; Cleminson, 2010, p. 179.

24. Expediente n. ${ }^{\circ} 2$ (1955), Juzgado Especial de Vagos y Maleantes de Bilbao, AHPB. Aunque la documentación es fragmentaria, sabemos que, al menos uno de los jóvenes que acudía a estas fiestas también fue condenado en la misma causa: Expediente n. ${ }^{\circ} 3$ (1955), Juzgado Especial de Vagos y Maleantes de Bilbao, AHPB.

25. Vázquez; Cleminson, 2010, pp. 33. 51, 65 y 70. Vázquez; Moreno, 1997, p. 16. Garza, 2002, 79 .

26. Documento 10032 (1951) Juzgado de Instrucción de Vitoria, Sección Judicial, AHE/EAH. Resulta necesario recordar que para el momento, la edad de diecinueve años estaba aún situada en la minoría de edad, Ley de 13 de Diciembre de 1943 sobre la fijación de la mayoría de edad Civil. BOE 13/12/1943. 
una práctica habitual del momento. Fue muy frecuente, en la documentación consultada, que tanto jueces como fiscales insistieran en juzgar los delitos sexuales bajo la forma del abuso deshonesto, que conllevaba una pena más dura que el de escándalo público. Hay que matizar que el delito de abusos deshonestos estaba en origen pensado para causas en las que las relaciones hubieran sido mantenidas por un adulto con un menor de doce años. El abogado defensor centró su alegato, no tanto en negar la existencia de los hechos sexuales, como en tratar de demostrar la inexistencia de trascendencia pública de los mismos entre la vecindad. Según su argumento, estos se habían producido sin «grave escándalo, ni [...] grave trascendencia» $\mathrm{y}$, por tanto, no habían ejercido daños en la colectividad, en la dimensión moral del ejemplo contaminante. Para el abogado quedaba demostrado en «el hecho de que [...] ha permanecido [oculto] durante un año y nueve meses». En resumidas cuentas, que no se había subvertido el mutismo católico sobre la sexualidad. Desafortunadamente, no contamos con la sentencia que cerró este proceso culpabilizando o absolviendo al procesado y, por tanto, desconocemos si estos argumentos tuvieron algún tipo de relevancia en la decisión del juez ${ }^{27}$. La existencia de actos sexuales parecía un lugar común entre la acusación y la defensa, aunque éstos, en sí mismos, no fueron tomados como evidencia absoluta de desviación sexual del procesado. Fue requerido, en este contexto de cambios, el concurso de un facultativo que pudiera diagnosticar definitivamente la homosexualidad del procesado. El informe del forense constituyó la prueba que más afianzó la imagen de desorden sexual del investigado, produciéndolo como un estado psicofísico aberrante. En las siguientes líneas, pueden ser apreciados los procesos para hacer surgir un «cuerpo» homosexual abyecto y desordenado en el terreno sexual y de género:

Que del resultado del reconocimiento y observación, aprecian dos fundamentos: en el primero, se observa un estado de aberración sexual (homosexualidad pederastia) que padece don [...], influenciado por la

27. Documento 10032 (1951) Juzgado de Instrucción de Vitoria, Sección Judicial, AHE/ EAH. Expediente abierto por el Juzgado de Instrucción de Vitoria. Las sentencias en causas de esta índole eran elevadas a las Audiencia Provinciales. De la consulta de los fondos pertenecientes a este nivel de la administración se puede constatar que no se conservan otras evidencias documentales de este proceso. Para la medicina legal del momento, el elemento de conexión entre los «abusos deshonestos» y el «escándalo público» era la expresión del «instinto sexual no controlado por la voluntad», López Gómez; Gisbert Calabuig, 1961, p. 3. 
educación recibida en los primeros estadios de la vida y principalmente en la época de la pubertad. Sin apelar a complejos de determinado orden, sabemos la influencia que sobre el examinado ejercía el apoyo maternal, muchas veces le hemos conocido acompañado de su madre cuando salía a hacer las visitas profesionales. Criado y educado en este ambiente, no se ha desarrollado en él la conciencia justa y exacta del carácter y finalidad del acto sexual ${ }^{28}$.

Aquí comienza la acción productiva, que Beatriz Preciado denominaría un ejercicio de «arquitectura corporal» ${ }^{29}$, transformando las prácticas ocasionales de este individuo en un tipo humano concreto e identificable. A partir de este momento, la voz del propio inculpado careció absolutamente de importancia. Toda capacidad de gestación de significados estuvo en las manos expertas del médico forense. Los términos homosexualidad y pederastia, empleados en el informe, pueden aquí entenderse de forma intercambiable, pues no remiten más que a un empleo arcaico de las categorías de la medicina forense del XIX. Más concretamente de las ideas desarrolladas por Tardieu, que en muchos casos aparecen «revisitadas» en las publicaciones médicas durante la dictadura ${ }^{30}$. Siguiendo las percepciones más misóginas de la época, la desviación sexual del paciente no es sino resultado de los cuidados inadecuados prestados por su madre. Esta concepción de la sexualidad como estado transitorio, mezcla de elementos congénitos y ambientales, remite a las teorías de la «intersexualidad anatómica», desarrolladas por Gregorio Marañón, que también fueron recuperadas durante los años cuarenta, entre otros, por los colaboradores de la Revista de Medicina Legal ${ }^{31}$. La teoría de la intersexualidad se sustentaba en la idea de que todos los cuerpos humanos se gestaban con una conformación anatómica «intersexual», pero que esta fase representaba un estado atávico o primitivo del desarrollo humano, caracterizado por falta de definición en términos sexuales, una condición que resultaba necesario superar. La solución, según Marañón, consistía en la correcta orientación de los sujetos hacia la diferencia sexual, configurándose como hombres y mujeres definiti-

28. Documento 10032 (1951) Juzgado de Instrucción de Vitoria, Sección Judicial, AHE/EAH.

29. Preciado, 2011, p. 27.

30. Gónzalez Bernal, 1949, pp. 167-175. Teorías médicas que seguían vigentes a finales de los años sesenta, Cleminson, 2005, pp. 142-146.

31. Martínez Selles, 1950, pp. 206-215. Medina, 2013, p. 38. 
vos, totales. En este sentido, no atribuía un peso rotundo a los factores constitucionales y, por tanto, la sociedad jugaba un papel decisivo en el control y orientación de las conductas de sus miembros ${ }^{32}$. Una teoría de la sexualidad que tuvo una demostradísima vigencia en el tiempo, como lo puso nuevamente de relieve el Discurso sobre la homosexualidad pronunciado por el Doctor Valentín Pérez Argiles, en la Real Academia de Medicina de Zaragoza, en $1959^{33}$. Un discurso sobre lo sexual que no resultó incompatible con una visión freudiana del síndrome de Edipo, que también puede vislumbrarse en el informe. Aunque la obra de Freud fue duramente denostada durante el primer franquismo, en la medicina legal fue empleada de forma estratégica, en la medida en que permitía estrechar los vínculos entre psiquiatría y control social, afianzando la imagen de «peligrosidad social» de los investigados. Eso sí, intentado alejarse de sus versiones más ortodoxas ${ }^{34}$.

La percepción de riesgo de desviación sexual durante la pubertad estuvo siempre presente entre las propuestas de la medicina durante el franquismo, así Antonio Vallejo Nágera reconocía la posibilidad de una «homosexualidad de transición» en esta etapa vital ${ }^{35}$. A partir de la década de los cincuenta, resulta mucho más frecuente en la documentación analizada que la responsabilidad de la normalización sexual de la descendencia comience a recaer en los progenitores, especialmente, y desde una perspectiva misógina, en la acción u omisión materna. En este sentido, los manuales, que abordaban la maternidad y formación de los hijos e hijas, responsabilizaban a las madres del desarrollo sexual inadecuado de su prole, recordándoles que «el deseo es fuerza motriz, que hay que encauzar» hacia la «vida sexual normal y sana» ${ }^{36}$. La recomendación tenía especial insistencia además cuando se refería a la crianza de varones. El informe médico continúa desarrollando esta idea de indefinición que caracterizaría al sujeto analizado:

32. Aresti, 2010, p. 198; Aresti, 2001, pp. 120-130; y Vázquez; Cleminson, 2011, pp. 91 y 99.

33. Molina Artaloytia, 2014, pp. 101-103; Martínez Vidal; Adam Donat, 2008, pp. 110-112.

34. El empleo de la teoría freudiana siempre generó tensiones en la medicina durante el franquismo, y cuando fue empleada, se insistía en la necesidad de aportarle una visión cristiana complementaria con el nacionalcatolicismo. Lévy Lazcano, 2016, pp. 145-174. Medina, 2013, p. 103. Molina, 2015, pp. 549-550 y 579.

35. Adam Donat; Martínez Vidal, 2004, pp. 60.

36. Roca mora, 1963, p, 51; Molina Artaloytia, 2015, p. 602; y Adam Donat; Martínez Vidal, 2004, pp. 52. 
Es indudable, la fuerza del factor constitucional que orienta a algunos homosexualmente y que en este caso ha carecido de intentos de orientación hacia la normalidad de las inclinaciones sexuales; ni siquiera siente como patológico su actual tendencia; ello indica el extremo al que los factores enunciados han desviado el criterio moral, social y sexual del examinado $[\ldots]^{37}$.

La medicina legal del momento atribuía una serie de características internas y externas a la conformación de los cuerpos homosexuales. Siguiendo con la comprensión marañoniana, el médico detectaba una serie de condicionantes constitucionales, que configuran al homosexual desde el nacimiento. Por tanto, en parte de sus formulaciones se concibe como una sustancia ontológica, adherida al individuo en sus orígenes. Sin embargo, aunque reconoce este condicionante, sobreentiende que su falta del control, del individuo sobre sí mismo y del entorno, ha sido el detonante de su desviación. Por ello, la culpabilización del sujeto aumenta, también en el sentido moral, pues aún aquejado de ese condicionante biológico, debió actuar decididamente para frenar su estado patológico, antes de la edad adulta. Seguramente aquí, aunque no aparecen explícitas, se sumen ideas relacionadas con el pecado, en las que los sujetos deben controlar la pulsión de sus instintos, con el fin de evitar dejarse llevar por ellos ${ }^{38}$. El hecho de no poner remedio a su situación patológica no sólo le convierte en un sujeto clínicamente no sano, sino que también le produce como un ser sin moralidad y en algo peligroso para la sociedad, que resulta necesario extirpar ${ }^{39}$. En este sentido existió un consenso social más amplio que el circunscrito a las valoraciones médicas y legales. El propio abogado defensor, en su alegato, tachó la conducta de su defendido de «repugnante» [...] en el orden moral y

37. Documento 10032 (1951) Juzgado de Instrucción de Vitoria, Sección Judicial, AHE/EAH.

38. Para la doctrina de la Iglesia evitar las tentaciones era un acto de voluntad y en casos de flaqueza, la solución era acudir a «postrarse ante el Sagrario de la Iglesia más próxima», González de Vega, 1957, pp. 62.

39. La voluntad, en el terreno sexual, representó también para la medicina y la justicia un elemento central a la hora de juzgar la conducta de los procesados. Evidencia de ello resulta la absolución de un procesado por «homosexualidad» por el Tribunal de Vagos y Maleantes de Bilbao, al entender que había demostrado un «afán de completa regeneración» a través de «próximo matrimonio», evitando aquellas «prácticas antinaturales de las que voluntariamente se apartó». Expediente n. ${ }^{\circ} 29$ (1957), Juzgado Especial de Vagos y Maleantes de Bilbao, AHPB). 
social» ${ }^{40}$, aunque no de responsable legal. Desde esta perspectiva, el «asco» a la sexualidad abyecta fue concebido como el mecanismo básico de regulación de la normalidad sexual y, por extensión, de separación entre conductas desviadas y sometidas al orden ${ }^{41}$. Para concluir, el médico también alegó desórdenes psíquicos en el individuo explorado:

En el segundo, [cabría destacar] el fondo psíquico de la personalidad del explorado, de temperamento tímido y apocado, donde los factores constitucionales sexuales han deformado la madurez sexual corporal ${ }^{42}$.

Así, el homosexual no era únicamente un desviado en el terreno físico y formativo, sino que también se revelaba en el plano psíquico. Es muy habitual que los expedientes médicos analizados diagnostiquen a los examinados signos de timidez. Esta percepción está directamente relacionada con los valores de género que resultaban adecuados para hombres y mujeres. La «timidez» era de este modo un síntoma directo de indefinición sexual, pues en este sentido a la masculinidad le correspondía un carácter «extrínseco agresivo» mientras la feminidad debía estar caracterizada por formas «concéntricas y mediadoras», tal como afirmaba el psiquiatra Juan José López Ibor en una de sus conferencias ${ }^{43}$. Algunos testigos interrogados, de la misma profesión que el denunciado, estimaban incluso que su conducta era impropia de una persona de su condición social y veían la relación con su madre como algo problemático y sospechoso. La condición de género y de clase colaboraban así en afianzar las sospechas de homosexualidad del investigado:

Entre sus compañeros de profesión está considerado psicológicamente como un anormal [...]. Rara vez se le ve en relación con personas de su posición social, de edad semejante o hacer la vida corriente de su profesión y situación sería corriente que hiciese y frecuentemente se le ve al lado de su madre con la que incluso va a espectáculos ${ }^{44}$.

40. Documento 10032 (1951) Juzgado de Instrucción de Vitoria, Sección Judicial, AHE/EAH.

41. Ahmed, 2015, pp. 134-151.

42. Documento 10032 (1951) Juzgado de Instrucción de Vitoria, Sección Judicial, AHE/EAH.

43. López Ibor, 1959, p. 25. García, 2017, pp. 223.

44. Documento 10144 (1951) Juzgado de Instrucción de Vitoria, Sección Judicial, AHE/EAH. 
Aquí la condición social del «homosexual» no sólo no actuó como un elemento que diluyó las apreciaciones de ciertas conductas como desviadas, sino que contribuyó a alargar las sombras de individuo anormal del procesado. Se entendía que desde su posición social debía dar ejemplo de buena conducta.

\section{Una anatomía indiscreta: el secreto siempre traicionado}

La trascendencia pública de las prácticas sexuales «desviadas» de los sectores acomodados de la sociedad comenzó a ser percibida como una «plaga social» sobre la que resultaba necesario prestar vigilancia. Aunque el Estado había asumido la tarea de ordenar en términos sexuales a la población a través de las instituciones judiciales, la Iglesia católica tampoco había renunciado a su papel de guía moral de la sociedad en este terreno, como evidencia este informe:

Merece especial mención la plaga social de la inversión por ser una plaga que se inicia en nuestro pueblo, habiendo tomado en pocos años caracteres bastante acusados. Hemos preguntado a vecinos relacionados con la medicina, y sacamos la conclusión de que la inversión está afectando de una manera grave a personas que eran consideradas como buenos feligreses. Es en la clase alta donde el problema presenta más gravedad; pero las otras clases sociales son también atacadas por este vicio[... $]^{45}$.

Este informe provenía de Getxo, uno de los municipios con las rentas más altas del País Vasco, lugar de vivienda de la aristocracia desde el siglo XIX. La alarma suscitada en el documento derivaba de una mezcla de factores de naturaleza religiosa, médica y social. Esta forma de entender la relación entre el pecado, la desviación sexual y el desorden social fue bastante común durante el franquismo. Desde las diferentes instancias de producción discursiva se entendía que trataba de fenómenos contagiosos

45. De La Rica Basagoiti, 1957, p. 122-123. La Junta Provincial de Vizcaya señalaba, años antes, que la «homosexualidad» era frecuente entre personas de «vida ociosa» que de la «masa común», Patronato de Protección a la Mujer: Informe sobre la Moralidad Pública en España. Memoria correspondiente a los años 1942 y 1952, Madrid, Graficas Ibéricas, 1954, p. 169. En términos nacionales, Mauricio Karl insistía en que la «Sodomía» es más propia de las «clases privilegiadas», Karl, 1956, p. 13. 
que amenazaban con expandirse socialmente y a los que, por tanto, había que ponerles freno actuando desde todos los frentes ${ }^{46}$.

A pesar de que estas dimensiones católica, médica y social estaban íntimamente ligadas, es posible desgranar las diferentes concepciones. La visión de la iglesia católica respecto a la homosexualidad seguía estando atravesada por la noción de caída en el pecado, y por tanto, se trataba de una cuestión de fe y buena conducta, de un ejercicio cristiano y moral del libre albedrío. Con todo ello, esta dimensión religiosa no permanecía al margen de visiones científicas coetáneas, evidenciadas a través de la categoría «inversión». No casualmente, la categoría de «inversión», con su capacidad de servir de confluencia a diferentes lógicas discursivas, fue la más frecuentemente empleada durante el franquismo para identificar la sexualidad «desordenada». En definitiva, lo que apreciamos es un diálogo entre visiones diversas en el proceso de conformación de un cuerpo homosexual, en un momento en que las visiones más esencialistas comenzaban a ocupar un espacio más central en la regulación sexual.

Siguiendo un eje temporal, en las próximas líneas analizaremos el caso de otro individuo acomodado procesado por su sexualidad ya en los años sesenta, en los que el «cuerpo homosexual» centralizó todas las consideraciones, siendo en sí mismo el detónate del proceso. El expediente número 392 de 1966 del Tribunal de Vagos y Maleantes de San Sebastián fue abierto a un «decorador» soltero y de 38 años, que había sido:

...detenido por los Inspectores del Servicio de Noche de esta Comisaria en la Sala de Fiestas «La Perla», a las doce horas del día de la fecha, cuando como en anteriores noches, y vestido de etiqueta, alternaba en el indicado establecimiento, a la espera de homosexuales, a cuya explotación se dedica habitualmente ${ }^{47}$.

46. El empleo de este lenguaje que conjuga lo católico y lo médico puede encontrarse en el Juez de Vagos y Maleantes Antonio Sabater Tomás cuando se refería a la homosexualidad como «impudicia contra natura» o recurría a la teoría de los «estados intersexuales». Sabater Tomás, 1962, pp. 175-180.

47. La sentencia del Juez terminó por condenarle al «internamiento en un establecimiento de trabajo por tiempo indeterminado no inferior a dos meses ni superior a un año». Aún así, en la terminología judicial del momento las codenas por homosexualidad eran denominadas como aplicación de «medidas de seguridad». Expediente n. 392 (1966), Juzgado Especial de Vagos y Maleantes de San Sebastián, AHPB. 
En la toma de declaración del inculpado se prestó especial atención, como fue siempre habitual en los procesos de la Justicia Especial de Vagos y Maleantes, a sus condiciones de vida. A esta cuestión el «decorador» contestó que desempeñaba esta profesión desde su llegada a San Sebastián y que, «teniendo a su cargo la instalación de escaparates, y también de las poblaciones donde tiene sucursal, ganando fijamente 10.000 pesetas al mes, y aparte de este sueldo tiene algún otro ingreso por encargarle otras casas por hacer». En la misma intervención, además, reconoció ser «invertido sexual», una confesión habitual en los detenidos que más bien se asemeja a un formalismo en la recogida de declaraciones ${ }^{48}$. No parece evidente que sus prácticas sexuales fuesen el elemento determinante que desembocara en la detención de la que fue objeto, más parece ser su actitud sospechosa en un lugar de encuentro homosexual lo que llamó la atención policial. El excesivo refinamiento en el uso del cuerpo masculino comenzaba a tabalearse como referente exclusivo de pertenencia social, dando lugar a sospechas de ambigüedad sexual, como también se advierte en otras detenciones. En el contexto de Madrid, en uno de los testimonios orales recogidos por Francisco Molina, el varón entrevistado reconoció haber sufrido hostigamiento policial y verse envuelto en algunas detenciones, en los lugares habituales de encuentro homosexual del momento, por su afición a «vestir de blanco», de forma elegante o usar «perfumes». Insistía en que, aunque su imagen cuidada correspondía a la del «señor respetable», había personas en su entorno «que le miraban mal» y que leían su hexis corporal como la representación inequívoca del «afeminado» ${ }^{49}$. Lo que se puede extraer de este testimonio, y de la documentación analizada hasta el momento, es que no hubo en la época una percepción social nítida en relación con los límites del refinamiento en los usos del cuerpo masculino, sino que existieron diversas visiones del cuerpo, que en términos foucaultianos, actuaron como campos tácticos de fuerza. Por ello, para certificar la «inversión» de los detenidos, la justicia acudió a la que se había convertido progresivamente en la voz autorizada a tales fines, en paralelo al proceso creciente de biologización de la sexualidad no norma-

48. Expediente n. 392 (1966), Juzgado Especial de Vagos y Maleantes de San Sebastián, AHPB.

49. Molina Artaloytia, 2015, pp. 610-611. De otro procesado en el mismo año también se hizo figurar la circunstancia de que viste «traje de etiqueta» en «el momento de su detención». Expediente n. 362 (1966), Juzgado Especial de Vagos y Maleantes de San Sebastián, AHPB. 
tiva, el médico forense. En los expedientes judiciales analizados, los informes médicos más que «descubrir» los indicios de desviación sexual en los cuerpos investigados, vinieron a corroborar las evidencias policiales. En el proceso del decorador de San Sebastián, el forense del Tribunal de Vagos y Maleantes, certificó con rotundidad el carácter homosexual del arrestado, expresándose en los siguientes términos:

Qué ha reconocido a [...] de 37 años, qué dice ser Decorador. - Genitales de buena conformación y tamaño, con verga algo retorcida, propia del invertido y del onanista inveterado; región anal muy depresiva o infundibular con esfínter permeable y hemorroides; signos típicos-. Caracterológicamente es de aspecto macho integral pero al hablar caen por tierra estas apreciaciones pues habla muy afeminado, con movimientos amanerados y feminoides, con lenguaje viscoso; niega su perversión y dice qué todo es envidia y envidia de la mala gente porqué él es el mejor decorador de San Sebastián.- En conjunto su soma y psiquismo es típico del invertido. Manifiesta anda con mujeres y ha tenido novias; ello no empoce ya en el lenguaje quevediano estos pervertidos veteranos le dan al pelo y a la lana y para cubrirse procuran hacerse acompañar con mujeres para que les vean sus amistades ${ }^{50}$.

Resulta especialmente representativo el lenguaje con el que el médico describe la exploración del procesado, en una mezcla de elementos provenientes del «saber científico», de la medicina forense, con otras muy propias de la cultura popular, en una redacción poco frecuente, si se compara con el resto de informes de la misma institución. Daría incluso la impresión que para este profesional, el lenguaje propiamente técnico le es insuficiente para «diagnosticar» las «evidencias» que se le presentan, y sólo el acervo popular fue capaz de expresar definitivamente su diagnóstico. Es la evidencia de una «medicalización truncada», que se caracteriza por la traducción a un vocabulario técnico las concepciones de un imaginario social más arcaico sobre la sexualidad, una práctica que fue muy habitual en el tratamiento de la homosexualidad desde finales del siglo XIX en España ${ }^{51}$.

50. Expediente n. 392 (1966), Juzgado Especial de Vagos y Maleantes de San Sebastián, AHPB.

51. Ha sido denominada como una «medicalización truncada» que atribuye a nuevas categorías significados «arcaicos». Vázquez; Cleminson, 2011, p. 21. Cleminson; Fernández; Vázquez, 2014, p. 376. 
El cuerpo cobró aquí una relevancia singular en el diagnóstico de sexualidad desviada, los genitales resultaban expresión de esta situación interna. En realidad, se volvía a remitir aquí a la medicina forense del siglo XIX ya citada con anterioridad y que entendía que los «pederastas» presentaban una configuración genital particular y diferenciada del resto de los individuos sexualmente «sanos». Esta genitalización de la sexualidad pasaba por la identificación física en los cuerpos, considerando la «llaga sodomítica» de la exploración anal el signo más identificable de homosexualidad pasiva. Esta operación pasaba por la consideración de ciertas partes del cuerpo como no sexuales, especialmente el ano, que como Deleuze y Guattari han señalado fue «el primero de todo los órganos en ser privatizado» ${ }^{52}$. Su «verga» algo «retorcida» era también evidencia de desviación puesto que el onanismo fue siempre una práctica que generaba sospechas y que en muchos casos se entendía como antesala de la homosexualidad adulta ${ }^{53}$.

El resto de la exploración nos remite al ya citado cuerpo «intersexual»o también denominado «constitución bisexual» en otras obras, pues la mezcla de caracteres de ambos sexos en un solo cuerpo es siempre signo de desviación interna que termina por aflorar y manifestarse al exterior. La «ausencia de vello» o una «VOZ aguda» resultaban signos de «anomalía constitucional» en los «intersexuales» que se hacían visibles exteriormente en «gestos, actitudes y «ademanes», e incluso al gusto por «adornarse y arreglarse como una mujer» ${ }^{54}$. Por tanto, el homosexual, como cuerpo ambiguo, siempre termina por desvelar aquello que de forma congénita contiene. La homosexualidad era entendida como preexistente a los actos y manifestaciones sociales, constituyendo un sustrato inalterable que acaba aflorando ante la mirada incisiva del médico o el juez. Situación advertible incluso aunque el detenido hubiese tratado de erradicar las sospechas a través hacerse acompañar de mujeres. Al mismo tiempo, esta misma sustancia se apodera del individuo produciendo una teleología de su existencia, es decir, que termina escapar a su control. El especialista simplemente tiene que admirar los cuerpos para extraer de su interior las verdades, el homosexual es el personaje que en todo está dominado por su sexualidad que siempre se im-

52. Gónzalez Bernal, 1949, pp. 167-168. López Gómez; Gisbert Calabuig, 1961, pp. 8-9 y 14. Preciado, 2011, p. 23.

53. De Echalecu, 1946, pp. 262-263.

54. Adam Donat; Martínez Vidal, 2004, p. 54. De Echalecu, 1946, pp. 265-266. López Gómez; Gisbert Calabuig, 1961, pp. 7-8. 
pone. Todos estos procesos remiten muy claramente a la idea que Michel Foucault había señalado, para patologizar la homosexualidad había que insistir «menos la enormidad del crimen que la monstruosidad del criminal, su incorregibilidad, y la salvaguarda de la sociedad $»^{55}$.

La recepción de estas transformaciones en los significados de la sexualidad no quedó circunscrita a las prácticas de las instancias judiciales exclusivamente. Algunos sectores acomodados comenzaron a percibir la homosexualidad como un elemento a extirpar de sus familias y pusieron en práctica diversas formas de disciplinamiento en sus hogares. De este proceso da buena cuenta el expediente $n^{\circ} 157$ (1966) del Tribunal de Vagos y Maleantes de San Sebastián, en el que una madre acude a denunciar ante la policía la conducta desordenada de uno de sus hijos. Podría tomarse este caso como una evidencia de interiorización en la vida cotidiana de las prescripciones anteriormente citadas, que asociaban la ausencia de normalidad sexual en la descendencia, con la falta de vigilancia y cuidado materno. Los factores exógenos y ambientales seguían siendo sancionados por los discursos médicos del momento como fuentes de influencia muy decisiva en la conformación de la persona ${ }^{56}$. Algunos años más tarde, Fernando Chamorro Gundin continuaba considerando una medida central de profilaxis contra la homosexualidad la actitud ejemplarizante del círculo familiar. El cambio más significativo del periodo lo represente el reconocimiento de la necesidad de instrucción adecuada en el terreno sexual para los padres ${ }^{57}$. La denunciante hizo constar su dificultad para orientar la conducta de su hijo en los tres años anteriores. Los acontecimientos se desataron cuando, a través del «servicio de la casa» se había enterado de las intenciones del joven de realizar un «viaje a Orense, en compañía de otro hombre». La familia llevaba tiempo sospechando de su «vida dudosa»y, aunque habían realizado esfuerzos, su hijo «no quiere trabajar, ni estudiar, hace vida rara frecuentado Cafeterías y alternado con otros jóvenes» ${ }^{58}$, es decir, no había querido comportarse como se esperaba de un hombre.

En los interrogatorios que figuran en el expediente el joven relató los instrumentos que la familia empleo para su canalización hacia el orden

55. Foucault, 1976, pp. 56-57 y 167.

56. López Gómez; Gisbert Calabuig, 1961, p. 4. Sabater Tomás, 1962, pp. 195-196. Sabater Tomás, 1962, pp. 175-180.

57. Chamorro Gundin, 1970, pp. 149 y 151.

58. Expediente n..$^{\circ} 157$ (1966), Juzgado Especial de Vagos y Maleantes de San Sebastián, AHPB. 
sexual. En un primer momento el medio para virilizar su conducta consistió en incorporarle al trabajo en la empresa de su padre, una actividad que no surtió los efectos deseados en él. Resulta más que evidente el vínculo entre masculinidad y trabajo en términos de género, no exclusivamente en términos de mantenimiento del hogar familiar, sino como expresión de control de sí mismo y de la naturaleza ${ }^{59}$. Aunque los saberes expertos reconocían el trabajo como algo consustancial a la masculinidad ordenada, de aquí podemos extraer la conclusión de que también se trató de un consenso social más general. Fracasado este primer intento de canalización, la familia recurrió entonces a la medicina como mecanismo transformador. El joven fue enviado a Barcelona al «Reformatorio de San Pedro Apóstol» y puesto «en tratamiento médico de Psiquiatría, con el Dr. Sarró». Tampoco este último procedimiento tuvo los efectos esperados. Como solución final, al menos en lo que conocemos, su madre decidió acudir a la justicia y denunciar las prácticas de su hijo que escapaban a la normalidad. Para el caso, el juez de Vagos y Maleantes no encontró responsabilidad legal y ordenó la puesta en libertad del joven. No podemos extraer de este proceso una conducta general de la población en relación a la interiorización de la norma sexual, pero sí apreciar las tensiones que estaban resultando en la reconfiguración de una masculinidad aceptable, que afectó a las clases medias y acomodadas de la sociedad durante el desarrollismo.

\section{Conclusiones}

El franquismo no desarrolló teorizaciones profundamente «nuevas» en relación con lo homosexual y, sin embargo, produjo transformaciones tremendamente significativas en su comprensión, gestión social y tratamiento. Las instituciones y actores sociales vinculados con el control de la misma, restituyeron teorías, instituciones y leyes de etapas anteriores, que en muchos casos hundían sus raíces en las últimas décadas del siglo XIX. Quizá el punto de inflexión lo represente la incorporación de una versión más «conservadora», que su propuesta inicial, de la teoría de la intersexualidad marañoniana, durante la década de los cincuenta. Pero, al mismo tiempo, no podemos restar peso a las compresiones de origen popular, que representaron un sustrato socialmente compartido, con parte de los saberes expertos o,

59. López Ibor, 1968, p. 336. 
al menos, en un diálogo bidireccional y constante con ellos. Lo que se nos muestra es un panorama complejo, de tensiones entre los actores sociales y las instancias represivas del régimen. En alguno de los casos analizados, llegando a emplear las propias instituciones del Estado, de forma estratégica, como mecanismo de normalización de los individuos disidentes en el seno familiar, como en el último de los procesos analizados.

Ha quedado demostrado como lo homosexual pasó de constituir una actividad pecaminosa a un personaje en la medida en que el cuerpo material fue adquiriendo relevancia en la identificación de la sexualidad abyecta. Seguramente el término foucaultiano de anatomía indiscreta sea el que mejor lo defina, como sustancia ontológica y teleológica, sobre la que los propios individuos dejaron de tener capacidad de control. La dimensión biológica de la sexualidad ocupó el espacio central en la identificación de los sujetos desviados, y seguramente, de la propia diferencia sexual que caracterizó la segunda etapa de la dictadura. La insistencia en la voluntad como mecanismo valorativo de la responsabilidad de los actos en materia sexual decreció, las voces de los sujetos comenzaron a carecer de entidad y, con ello, los saberes expertos comenzaron a recuperar un cierto papel en la ordenación de la sociedad, aunque nunca en oposición absoluta con los preceptos del catolicismo.

Lo homosexual fue constituido progresivamente a partir de la década de los cincuenta como un cuerpo invertido. Como queda patente, el género fue capaz de restar relevancia a otras variables como la condición social o laboral, entre otras, a la hora de juzgar y condenar la sexualidad no normativa. Las prácticas sexuales y los mismos testimonios de los interrogados, carecieron de valor frente al afeminamiento escandaloso. En este sentido, la condición acomodada no supuso un freno absoluto, y en todos los casos, al castigo de los procesados en los expedientes analizados. En algunos casos, incluso, pudo representar un elemento agravante. De los miembros de los grupos de cierta posición social se esperaba unas conductas morales, sexuales y de género acorde a los valores que la Iglesia y el régimen habían inculcado a la sociedad. Frente a estos, las prácticas homosexuales de varones que se aproximaban a la virilidad, según el imaginario social del momento, fueron generalmente exculpadas, desde las instancias normativas, tanto en los casos en los que los procesados tuviesen un origen acomodado como cuando provenían de los entornos más humildes. En este escenario, la renuncia al afeminamiento fue conformándose progresivamente como parte sustancial de la nueva masculinidad aristocrática y de clase, a partir de los años cincuenta. 
Afeminados de vida ociosa: sexualidad, género y clase social durante el franquismo

\section{Fuentes}

Archivo Histórico Provincial del Bizkaia (AHPB).

Archivo Histórico de Euskadi/Euskadiko Artxibo Historikoa (AHE/EAH).

\section{Bibliografía}

AdAm donAt, Antoni; MARTínez VidAL, Àlvar: «Consideraciones sobre tan repugnante tendencia sexual»: la homosexualidad en la psiquiatría del franquismo», Orientaciones. Revista de homosexualidades, 7 (2004), pp. 51-72.

AHMED, Sara: La política cultural de las emociones. México, Universidad Nacional Autónoma de México, 2015.

AlbARRACín, Matilde: «Identidad(es) lésbica(s) en el primer franquismo», Raquel OsBORne (ed.): Mujeres bajo sospecha. Memoria y sexualidad 1930-1980, Madrid, Fundamentos, 2012, pp. 69- 87.

AlCALDE, Ángel: «El descanso del guerrero: la transformación de la masculinidad excombatiente franquista (1939-1965)», Historia y Política, 37 (2017), pp. 177-208.

AlEGRE, David: «Coser y desgarrar, conservar y arrojar»: visiones del enemigo y estrategias de supervivencia psíquica en la División Azul», Cuadernos de Historia Contemporánea, 2012, vol. 34, pp. 119-144.

Álvarez Fernández, Carlos: «Jóvenes en "el lecho de Procusto". Una aproximación a los ideales de género de posguerra», Arenal, 27:2 (2020), pp. 331-354.

ARESTI, Nerea: Médicos, donjuanes y mujeres modernas: los ideales de feminidad y masculinidad en el primer tercio del siglo $X X$, Bilbao, Servicio Editorial Universidad del País Vasco/Euskal Herriko Unibertsitatea, 2001.

ARESTI, Nerea: Masculinidades en tela de juicio: hombres y género en el primer tercio del siglo XX, Madrid, Cátedra, 2010.

Aresti, Nerea: «The Battle to Define Spanish Manhood», Morcillo, Aurora (ed.), Memory and Cultural History of the Spanish Civil War. Leiden-Boston, Brill, 2014, pp. 147-177.

ARnalte, Arturo: Redada de violetas: la represión de los homosexuales durante el franquismo, Madrid; La Esfera de los libros, 2003.

BAIDEZ, Nathan: Vagos, maleantes... y homosexuales. La represión a los homosexuales durante el franquismo, Barcelona, Malhivern, 2007.

Box, Zira: «Masculinidad en línea recta: a propósito del pensamiento binario del fascismo español», en Aresti, Nerea; Peters, Karin; BrüHne, Julia (eds.): ¿La España invertebrada? Masculinidad y nación a comienzos del siglo XX, Comares, Granada, 2016, pp. 223-238.

Box, Zira: «Cuerpo y nación: sobre la España vertical y la imagen del hombre», Ayer 107, 2017, pp. 205-228. 
Butler, Judith: Deshacer el género, Barcelona, Buenos Aires, México, Paidós, 2010.

CABrera, Miguel Ángel: Historia, lenguaje y teoría de la sociedad, Madrid, Cátedra, 2001.

CAYuela, Salvador: Por la grandeza de la patria: la biopolítica en la España de Franco (1939-1975), Madrid, Fondo de Cultura Económica de España, 2014, pp. 39 y 207.

Chamorro Gundin, Fernando: Resultados obtenidos con técnicas proyectivas en una muestra de 200 delincuentes homosexuales españoles, Madrid, Dirección General de Instituciones Penitenciarias, 1970.

Chamouleau, Brice: Tiran al maricón: los fantasmas queer de la democracia (1970-1988). Una interpretación de las subjetividades gais ante el Estado español, Madrid, Akal, 2017.

Cleminson, Richard: «Instancias de la biopolítica en España, siglos XX y XXI», en Ugarte PÉRez, Javier (comp.): La administración de la vida. Estudios bipolíticos, Barcelona, Anthropos, 2005, pp. 127-152.

Cleminson, Richard: «La obra sexológica del Dr. Martín de Lucenay: entre el conocimiento científico y la recepción popular de la ciencia sexológica en España a principios del siglo xx», en Jean-Louis GuEREÑA (ed.): La sexualidad en la España contemporánea (1800-1950), Cádiz, Universidad de Cádiz, 2011, pp. 163-188.

Cleminson, Richard; Fernández, Pura; VÁzquez García, Francisco: «The Social Significance of Homosexual Scandals in Spain in the Late Nineteenth Century», Journal of the History of Sexuality, 23:3 (2014), pp. 358-382.

Cuello, Eugenio: Código Penal. Texto refundido de 1944 y Leyes Penales Especiales, Madrid, Ministerio de Justicia y Consejo Superior de Investigaciones Científicas, 1946.

De Echalecu, Francisco Javier: Psicopatología, Madrid, Publicaciones del Patronato de Protección a la Mujer, 1946, pp. 262-263.

De la Rica Basagoiti, José Miguel: La Parroquia de Nuestra Señora de las Mercedes de las Arenas. Estudio de Sociología Religiosa, Bilbao, Patronato de la Universidad de Deusto, Universidad Comercial, 1957.

Di FEBo, Guiliana: «El "Monje Guerrero": identidad de género en los modelos franquistas durante la Guerra Civil», Las mujeres y la Guerra Civil española, III Jornadas de Estudios Monográficos, Salamanca, 1989 (Madrid, Ministerio de Asuntos Sociales e Instituto de la Mujer, 1991), pp. 202-210.

Di FEBo, Guiliana: «"Nuevo Estado”, nacionalcatolicismo y género», NiELFA, Gloria: Mujeres y hombres en la España franquista: sociedad, economía, política, cultura, Madrid, Editorial Complutense, 2003, pp. 19-44.

DíAZ, Abel: «Los "invertidos": homosexualidad(es) y género en el primer franquismo», Cuadernos de Historia Contemporánea, 41 (2019), pp. 333-353. 
DíAZ FreIRE, José Javier: «Cuerpos en conflicto. La construcción de la identidad y la diferencia en el País Vasco a finales del siglo XIX», en Mary NASH, Diana MARRE (eds.): El desafío de la diferencia: representaciones culturales e identidades de género, raza y clase, Bilbao, Universidad del País Vasco/ Euskal Herriko Unibertsitatea, 2003, pp. 61-94, pp. 66-70.

DíAZ FreIRE, José Javier: «Cuerpo a cuerpo con el giro lingüístico» en Arenal, 14:1 (2007), pp. 5-29.

Domingo, Victoriano: Los homosexuales frente a la ley. Los juristas opinan, Barcelona, Plaza \& Janes, 1977.

Foucault, Michel: Historia de la sexualidad. Vol. 1. La voluntad del saber, Madrid, Siglo XXI, 1976.

GArcía, Mónica: «Sexualidad y armonía conyugal en la España franquista. Representaciones de género en manuales sexuales y conyugales publicados entre 1946 y 1968», Ayer, 105-1(2017), pp. 215-248.

Garza, Federico: Quemando mariposas. Sodomía e imperio en Andalucía y México en los siglos XVI-XVII, Barcelona, Laertes, 2002.

GÓNZALEZ BERNAL: «La exploración en afrodisiología», Revista de Medicina Legal, 38-39 (1949), pp. 167-175.

GonzÁlez de Vega, Aresio: Para ti..., soldado. Manual del Soldado, Madrid, Ediciones de Acción Católica, 1957.

GoNZÁLEZ, Teresa: «Monje y soldado. La imagen masculina durante el franquismo», en Revista Internacional de Ciencias del Deporte, 1:1 (2005), pp. 64-83.

HEREDIA, Iván: «Control y exclusión social: la Ley de Vagos y Maleantes en el primer franquismo», Universo de micromundos. VI Congreso de Historia Local de Aragón, 2009, pp. 109-120.

HuARD, Geoffroy: Los antisociales: Historia de la homosexualidad en Barcelona y París. 1945-1975, Madrid, Marcial Pons, 2014.

HuARD, Geoffroy: «Los homosexuales en Barcelona bajo el franquismo. Prostitución, clase social y visibilidad entre 1956 y 1980», en Franquisme\&Transició. Revista d'Història i de Cultura 4 (2016), pp. 127-151.

HuARD, Geoffroy: «Los "invertidos" en Barcelona durante el franquismo y la construcción de la memoria gay. Un caso de cambio de sexo reconocido legalmente en 1977», en GALLEGO FrANCO, Henar (ed.): Feminidades y masculinidades en la historiografía de género, Granada, Comares, 2018, pp. 213- 222.

KARL, Mauricio: Sodomitas, Madrid, Nos, 1956.

KRYLOVA, Anna: «Gender Binary and the Limits of Poststructuralist Method», Gender\&History, 28:2 (2016), pp. 307-323.

LAQUeUR, Thomas: La construcción del sexo. Cuerpo y género desde los griegos hasta Freud, Madrid, Cátedra, 1994.

LÉVY LAZCANO, Silvia: «Prevenir, rehabilitar y sancionar. La incorporación de las ideas de psicoanalíticas en la psiquiatría forense (1930-1950), en CAMPOS, Ricardo; GonzÁlez de PABlo, Ángel (coords.): Psiquiatría e higiene mental 
durante el primer franquismo: rupturas y continuidades, Madrid, Libros de la Catarata, 2016, pp. 145-174.

López Gómez, Leopoldo; Gisbert Calabuig, Juan Antonio: Tratado de Medicina Legal II, Valencia, Sabater, 1961.

LóPEz IBOR, Juan José (dir.): El libro de la vida sexual, Barcelona, Danae, 1968.

LÓPEZ IBOR, Juan José: El misterio de la feminidad (conferencia pronunciada el día 29 de septiembre de 1958 en el Teatro «GUIMERÁ» de Santa Cruz de Tenerife, con el motivo de la inauguración de Aula de la Cultura). Aula de Cultura de Tenerife, 1959.

Martínez Selles: «Afrodisiología Médico-Legal», en Revista de Medicina Legal, 50-51 (1950), pp. 206-215.

Martínez Vidal, Àlvar; Adam Donat, Antoni: «Homosexuality, psychiatry and legal medice in Franco's regime and Democratic Transition in Spain (1936-1979), en ANDRESEN, Astri; GrønLIE, Tore; HubBARD, William; RYYMIN, Teemu; AtLE, Skalevag (eds.): Citizens, Courtrooms, Crossings, Stein Rokkan Centre for Social Studies, 2008, pp. 107- 118.

Medina, María Rosa: Ciencia y sabiduría del amor. Una historia cultural del franquismo (1940-1960), Madrid, Tiempo Emulado, 2013.

MirA, Alberto: De Sodoma a Chueca: una historia cultural de la homosexualidad en España en el siglo XX, Barcelona-Madrid, Egales. 2007.

Molina Artaloytia, Francisco: Estigmas, diagnosis e interacción: un análisis epistemológico y axiológico de los discursos biomédicos sobre la homosexualidad en los autoritarismos ibéricos del siglo XX, Tesis doctoral, Universidad Nacional de Educación a Distancia, 2015.

Molina ARtaloytia, Francisco: «"Rigor en ocasiones, caridad siempre, simpatía nunca": la homosexualidad en discursos paradigmáticos de la medicina forense y el derecho penal franquistas», en PEREIRA, Ana Leonor; Pita, João Rui (dir.): IV Jornadas Internacionais de História da Psiquiatria e Saúde Mental, Coimbra, Centro de Estudos Interdisciplinares do Século XX da Universidade de Coimbra-CEIS20, 2014, pp. 99-106.

MORA GASPAR, Víctor: Al margen de la naturaleza: la persecución de la homosexualidad durante el franquismo. Leyes, terapias y condenas, Barcelona, Debate, 2016.

MorcILlo, Aurora: En cuerpo y alma. Ser mujer en tiempos de Franco, Madrid, Siglo XXI, 2015.

NASH, Mary: «Representaciones culturales y discursos de género, raza y clase en la construcción de la sociedad europea contemporánea», en Mary NASH; Diana MARRE (eds.): El desafío de la diferencia: representaciones culturales e identidades de género, raza y clase, Bilbao, Servicio Editorial. Universidad del País Vasco/Euskal Herriko Unibertsitatea, 2003, pp. 21-35.

OlmEDA, Fernando: El látigo y la pluma: homosexuales en la España de Franco, Madrid, Oberón, 2004. 
Preciado, Beatriz: Manifiesto contrasexual, Barcelona, Anagrama, 2011. Rincón, Aintzane: Representaciones de género en el cine español (1939-1982): figuras y fisuras, Madrid, Centro de Estudios Políticos y Constitucionales, Universidad de Santiago de Compostela, 2014.

RoCAMORA, María Luisa: La mujer, la madre y el niño, Barcelona, Gasso, 1963.

Rosón VILLENA, María: «El álbum fotográfico del falangista. Género y memoria en la posguerra española», en Revista de Dialectología y Tradiciones Populares, vol. LXVIII, n. ${ }^{\circ} 1$ (2013) pp. 215-238.

SABATER TOMÁs, Antonio: Gamberros, homosexuales, vagos y maleantes (estudio jurídico-sociológico), Barcelona, Editorial Hispano Europea, 1962.

ScotT, Joan: «Género: ¿todavía una categoría útil para el análisis?», La manzana de la discordia, 6-1 (2011), pp. 95-101.

SosA, Miguel Ángel: Viaje al centro de la infamia, Las Palmas de Gran Canaria, Anroart, 2006.

TERRASA MATEU, Jordi: Control, represión y reeducación de los homosexuales durante el franquismo y el inicio de la transición, Tesis Doctoral, Universitat de Barcelona, 2016.

Terrasa Mateu, Jordi: «Estudio jurídico de la legislación represiva franquista», Orientaciones. Revista de homosexualidades, 7 (2004), pp. 83-100.

UGARTE, Javier (ed.): Una discriminación universal: la homosexualidad bajo el franquismo y la transición, Madrid, Egales, 2008.

UGARTE, Javier: Las circunstancias obligan: homoerotismo, identidad y resistencia, Barcelona-Madrid, Egales, 2011.

UGARTE, Javier: «Entre el pecado y la enfermedad», Orientaciones. Revista de homosexualidades, 7 (2004), pp. 7-26.

VAlverde, Salvador (coord.): Miguel de Molina. Botín de guerra: autobiografía, Barcelona, Planeta, 1998.

VÁzQuez García, Francisco; Cleminson, Richard: «"Quien con niños se junta”: la infancia y la iniciación homosexualista (1850-1936), en Rafael VÉLEZ (ed.): Géneros externos/externos genéricos: la política cultural del discurso pornográfico, Cádiz, Universidad de Cádiz, 2006, pp. 11-39.

VÁzQuez GARcía, Francisco: «El discurso médico y la invención del homosexual», Asclepio, 53-2 (2001), pp. 143-162.

VÁzQuez García, Francisco: «Homosexualidades. Presentación», Ayer, 87 (2012), pp. 13-21.

VÁzQueZ GARCía, Francisco: «Políticas transgénicas y ciencias sociales: por un construccionismo bien temperado», Seminario Teoría Queer: de la transgresión a la transformación social, Centro de Estudios Andaluces (2009). pp. 3-14. [https://www.centrodeestudiosandaluces.es/datos/factoriaideas/ PN03_09.pdf].

VÁzQuez GARcía, Francisco: «Sexo y razón (1997), diecisiete años después». Cuadernos de Historia Contemporánea, 40 (2018), pp. 115-128. 
VÁzquez García, Francisco; Cleminson, Richard: Los invisibles. Una historia de la homosexualidad masculina en España, 1850-1939, Granada, Comares, 2011 , p. 267.

VÁZQuez GarCía, Francisco; MoReno, Andrés: Sexo y razón. Una genealogía de la moral sexual en España (siglos XVI-XX), Madrid, Akal, 1997.

VINCENT, Mary: «La masculinidad en la construcción del nacionalcatolicismo después de la Guerra Civil», en GALLEGo FranCO, Henar (ed.): Feminidades y masculinidades en la historiografía de género, Granada, Comares, 2018, pp. 127- 159.

VINCENT, Mary: «La reafirmación de la masculinidad en la cruzada franquista», Cuadernos de Historia Contemporánea, 28(2006), pp. 135-151.

\section{Financiación y agradecimientos}

Este trabajo se enmarca el Grupo de Investigación «La experiencia de la sociedad moderna en España 1870-1990, financiado por la UPV/EHU (Código GIU08/15) y en el marco del proyecto de investigación «La experiencia de la sociedad moderna en España: Emociones, relaciones de género y subjetividades (siglos XIX y XX)», código: HAR2016-78223-C2-1-P, financiado por el Ministerio de Economía, Industria y Competitividad y el Fondo Social Europeo, FEDER. Quisiera mostrar mi más sincero agradecimiento a Nerea Aresti por sus excelentes aportaciones y consejos en la realización de este trabajo.

\section{Datos del autor}

Abel Díaz es doctorando en Historia Contemporánea, en el Departamento de Historia Contemporánea, de la Universidad del País Vasco. Se encuentra inmerso en el desarrollo de su proyecto de tesis titulado "Homosexualidad y masculinidad normativa en el franquismo (1939-1976)». Su investigación está centrada en el análisis de las transformaciones de los significados en torno a lo homosexual, durante la dictadura franquista, en los diferentes órdenes sociales e institucionales. En este sentido, sus preocupaciones se centran en el estudio de los vínculos existentes entre la sexualidad no normativa, las regulaciones de género y, por extensión, la configuración del orden social franquista. En la actualidad es miembro del grupo de investigación Experiencia Moderna (UPV/EHU) y ha efectuado una estancia de investigación en el Instituto de Investigaciones Gino Germani (IIGG) de la Universidad de Buenos Aires, en 2019. 